\title{
Serum Homocysteine and its Association with Lipid Profile in Type 2 Diabetic Patients
}

\author{
Majumder $\mathrm{M}^{1}$, Mollah $\mathrm{FH}^{2}$, Fariduddin $\mathrm{M}^{3}$, Ehsan $\mathrm{SM}^{4}$, Ferdous $\mathrm{SA}^{5}$
}

Conflict of Interest: None Received: $21-01-2018$ Accepted: $08-05-2018$ www.banglajol.info/index.php/JSSMC

\section{Key Words:}

Diabetes Mellitus, Hyperhomocysteinemia, lipid profile.

\begin{abstract}
:
Background: Diabetes accounts for almost $6 \%$ of total global mortality, with $50 \%$ of diabetesassociated deaths being attributed to cardiovascular disease (CVD). Prevalence of type 2 diabetes in rural Bangladeshi and in urban Bangladeshi is found to be $7.2 \%$ and $10.5 \%$ respectively. People of developing countries suffer from the disease at earlier age than that of developed countries. Among the diabetic patients, vascular complications represent a major cause of morbidity and mortality. Diabetes is commonly accompanied by other cardiovascular risk factors: dyslipidemia, hypertension, and increased prothrombotic factors. Total plasma homocysteine ( $t H c y)$ is an emerging CVD risk factor. Insulin resistance and hyperinsulinemia in diabetes mellitus along with increased homocysteine is thought to cause endothelial dysfunction. Endothelial dysfunction together with other factors such as dyslipidemia, microalbuminemia etc. causes cardiovascular disease.
\end{abstract}

Objectives: Objective of the study was to evaluate serum total homocysteine level and to correlate it with fasting lipid profile in type 2 diabetic patients.

Methodology: This cross sectional study was conducted during the period of July 2011- June 2013 on 95 patients of type 2 diabetes mellitus, attending the Endocrine OPD of Bangabandhu Sheikh Mujib Medical University (BSMMU). The study was carried out in the Department of Biochemistry, Bangabandhu Sheikh Mujib Medical University, Shahbag, Dhaka. Study subjects were selected by purposive and convenient sampling technique.

Result: Study subjects were categorized according to the presence or absence of hyperhomocysteinemia. Among the total study population hyperhomocysteinemia was found in $21.05 \%$. Among them number of male was greater. The study population had mean serum total cholesterol 198.34 $\pm 39.62(\mathrm{mg} / \mathrm{dl})$, triacylglycerol 198.91 $\pm 116.71(\mathrm{mg} / \mathrm{dl}), \mathrm{LDL} 126.75 \pm 35.38(\mathrm{mg} /$ dl), $H D L 34.35 \pm 8.31(\mathrm{mg} / \mathrm{dl}), T C: H D L=15.67 \pm 6.07: 1$, and $L D L: H D L=9.94 \pm 3.88: 1$ Independant sample $t$ test showed that there was significant inverse association of hyperhomocysteinemia with HDL. Other parameters of lipid profile and lipid ratios did not show any significant association.

Conclusions: Around one fifth of the type 2 diabetic patients had hyperhomocysteinemia. Significant inverse association was present between hyperhomocysteinemia and HDL. Other parameters of lipid profile and lipid ratios did not show any significant association.

[J Shaheed Suhrawardy Med Coll 2018; 10(1): 42-46] DOI: http://dx.doi.org/10.3329/jssmc.v10i1.38903
1. Dr. Moitreyee Majumder, Associate Professor, Dept of Biochemistry, ShSMC

2. Prof. Forhadul Hoque Mollah, Professor, Department of Biochemistry, BSMMU.

3. Prof. Md. Fariduddin, Professor of Endocrine Medicine, BSMMU

4. Dr. Sharif Mohammad Ehsan,Assistant Professor \& Head, Dept of Biochemistry Abdul Malek Ukil Medical College,Noakhali

5. Dr. Shamim Ara Ferdous, Lecturer, Dept of Biochemistry, ShSMC

Correspondence to: Dr. Moitreyee Majumder, Associate Professor, Dept of Biochemistry, Shaheed Suhrawardy Medical College, Mob.01712109664 email: moitreyeemajumder@gmail.com

\section{Introduction:}

Non-communicable diseases have been established as a clear threat not only to human health, but also to development and economic growth. Diabetes mellitus is one of the five major non-communicable diseases which were once concerned as "disease of affluence" has now encroached in developing countries. Type 2 diabetes accounts for $90-95 \%$ of all diabetic condition. Diabetes itself is not a high mortality condition, but is a major risk factor for other causes of death.People of developing countries suffer from the disease at earlier age than that of developed countries. ${ }^{1}$ 
Prevalence of type 2 diabetes in rural Bangladeshi and in urban Bangladeshi is found to be $7.2 \%$ and $10.5 \%$ respectively. ${ }^{2,3}$ Individuals with diabetes have twice the incident myocardial infarction (MI) rate as the general population, and survival rates are lower among individuals with diabetes once they have an adverse cardiovascular event. ${ }^{4}$ Among the long-term complications of diabetes mellitus, vascular complications represent a major cause of morbidity and mortality in these patients. The vascular complications of diabetes mellitus include coronary heart disease (CHD), stroke, peripheral arterial disease, nephropathy, retinopathy, and possibly neuropathy and cardiomyopathy. These complications have opportunities for their prevention. ${ }^{5}$ Diabetes is commonly accompanied by other cardiovascular risk factors: dyslipidemia, hypertension, and increased prothrombotic factors. ${ }^{6}$ Total plasma homocysteine (tHcy) is an emerging CVD risk factor. $^{7}$ Normal adult serum homocysteine level is 5$15 \mu \mathrm{mol} / \mathrm{L}$. Hyperhomocystinemia has been classified as: Moderate (Hcy $>15$ to $30 \mathrm{imol} / \mathrm{L}$ ), intermediate (Hcy> 30 to $100 \mathrm{ìmol} / \mathrm{L})$ and severe $(>100 \mathrm{ìmol} / \mathrm{L}) .{ }^{8}$ Hyperhomocysteinemia is associated with an increased risk for many disorders, including vascular and neurodegenerative diseases, autoimmune disorders, birth defects, diabetes, renal disease, osteoporosis, neuropsychiatric disorders, and cancer. ${ }^{9}$ Little is known about the impact of hyperhomocysteinemia among type $2 \mathrm{DM}^{7}$ Putative mechanisms of atherothrombosis in hyperhomocysteinemia include endothelial cell injury, endothelial dysfunction, increased vascular smooth muscle cell growth, increased platelet adhesiveness, enhanced LDL oxidation and deposition in the arterial wall, and direct activation of the coagulation cascade. ${ }^{10}$ Insulin resistance and hyperinsulinemia in diabetes mellitus along with increased homocysteine is thought to cause endothelial dysfunction. Endothelial dysfunction together with other factors such as dyslipidemia, microalbuminemia etc. causes cardiovascular disease. ${ }^{11}$ Dyslipidemia is one of the major risk factors for cardiovascular disease in diabetes mellitus. American Association of Clinical Endocrinologists (AACE) are in agreement with NCEP ATP III that LDL-C is central in the diagnosis of dyslipidemia. Any LDL-C level above $100 \mathrm{mg} / \mathrm{dL}$ appears to promote atherogenesis (NCEP-ATP III).

The characteristic features of diabetic dyslipidemia are a high plasma triglyceride concentration, low HDL cholesterol concentration and increased concentration of small dense LDL-cholesterol particles. The lipid changes associated with diabetes mellitus are attributed to increased free fatty acid flux secondary to insulin resistance. ${ }^{12}$
Diabetic patients having hyperhomocysteinemia suffer from increased mortality and morbidity from CVD events. Hyperhomocysteinemia can be corrected with vitamin therapy. ${ }^{13}$ If the study result shows that the diabetic patients have higher levels of serum homocysteine and is associated with dislipidemia, there might be scope of primary and secondary prevention of cardiovascular disease in those patients.

With this aim the study was conducted to assess the serum homocysteine status and lipid profile of the patients of type 2 diabetic patients and to correlate serum homocysteine with lipid profile. This will provide valuable baseline information about diabetic patients for further study in this arena, so that preventive measures can be taken at an early stage.

\section{Methodology:}

This cross sectional study was conducted in the department of Biochemistry, Bangabandhu Sheikh Mujib Medical University(BSMMU)from July 2011 to June 2013. Sample was collected from 95 type 2 diabetic patients aged between 30-70 years attending the Endocrinology department of BSMMU. Pregnant women, patients suffering from known heart disease or from diabetic nephropathy and patients receiving fenofibrate were excluded from the study. According to the hospital records patients were primarily selected. After enrollment, purpose and procedure of the study was explained in details and informed written consent was taken from all study subjects. With all aseptic precaution $10 \mathrm{ml}$ of venous blood was drawn from anticubital vein after overnight fasting (12 hrs) in a disposable plastic syringe, it was delivered into a clean dry test tube and kept in standing position till clot formation. Then serum was separated by centrifuging at $3000 \mathrm{rpm}$ for 5 minutes and was collected in ependrop tube and labeled properly. Estimation of serum glucose concentration was done by Glucose oxidase (GOD-PAP) method, serum fasting homocysteine( tHCY)by Fluorescence Polarization Immunoassay (FPIA) in IMx analyzer by Abbott Axsym system. Estimation of serum fasting total cholesterol by CHOL method, Estimation of serum fasting Triglyceride by TGL method, Estimation of serum fasting HDL by AHDL method (Siemens Healthcare Diagnostics Inc 2008); Estimation of serum fasting LDL was calculated by using Friedewald's formula: Analysis was done in the Department of Biochemistry,BSMMU.

Adult normal Serum level of homocysteine: $5-15 \mu \mathrm{mol} / \mathrm{L}$, Lipid profile: S.total cholesterol: $<200 \mathrm{mg} \%$, LDL-c: $<130 \mathrm{mg} \%$, TAG: $<150 \mathrm{mg} \%$, HDL-c: $>40 \mathrm{mg} \%$

After data collection they were checked, cleaned and edited for any discrepency.Data were analysed using SPSS.t-test, chi square test, correlation regression test were done. 


\section{Result}

\section{Table 1}

Biochemical Parameters of the Study Subjects

\begin{tabular}{ccc} 
Sample Size & Parameters & $(\mathrm{m} \pm \mathrm{SD})$ \\
\hline $\mathrm{n}=95$ & TC $(\mathrm{mg} / \mathrm{dl})$ & $198.34 \pm 39.62$ \\
& TAG $(\mathrm{mg} / \mathrm{dl})$ & $198.91 \pm 116.71$ \\
LDL $(\mathrm{mg} / \mathrm{dl})$ & $126.75 \pm 35.38$ \\
HDL $(\mathrm{mg} / \mathrm{dl})$ & $34.35 \pm 8.31$ \\
TC $: \mathrm{HDL}$ & $15.67 \pm 6.07: 1$ \\
LDL $: \mathrm{HDL}$ & $9.94 \pm 3.88: 1$ \\
& tHCY $(\mu \mathrm{mol} / \mathrm{l})$ & $11.81 \pm 4.09$ \\
\hline
\end{tabular}

Table 1 shows that mean total cholesterol was within normal limit in the study population. Other components of the lipid profile were beyond normal range. Serum tHcy was within normal range.

Table-II

Distribution of the Study Subjects According to Presence of Hyperhomocysteinemia

Hyperhomocy- Male Female Total(n) \% steinemia

\begin{tabular}{lcccc}
\hline Absent & 31 & 44 & 75 & 78.95 \\
Present & 13 & 7 & 20 & 21.05 \\
\hline Total & $44(47.4 \%)$ & $51(52.6 \%)$ & 95 & 100 \\
\hline
\end{tabular}

Table II shows that among the study population $21.05 \%$ had hyperhomocysteinemia and $78.95 \%$ had no hyperhomocysteinemia. Among the normohomocysteinemics, 31 were male and 44 were female. Among the hyperhomocysteinemics, 13 were male and 7 were female.

\section{Table-III}

Lipid profile of the study subjects with or without Hyperhomocysteinemia

Parameters Hyperhomo Normohomocysteinemia cysteinemia

\begin{tabular}{|c|c|}
\hline$(n=20)$ & $(n=75)$ \\
\hline $\mathrm{m} \pm \mathrm{SD}$ & $\mathrm{m} \pm \mathrm{SD}$ \\
\hline
\end{tabular}

\begin{tabular}{llllll}
\hline $\mathrm{TC}(\mathrm{mg} / \mathrm{dl})$ & $186.4 \pm 32.53$ & $201.52 \pm 40.91$ & -1.5 & 0.13 & $\mathrm{NS}$
\end{tabular}

TG(mg/dl) $180.55 \pm 74.25 \quad 203.81 \pm 125.58 \quad-7.9 \quad 0.43 \quad \mathrm{NS}$

$\begin{array}{llllll}\mathrm{LDL}(\mathrm{mg} / \mathrm{dl}) & 118.9 \pm 31.4 & 129.03 \pm 36.35 & -1.13 & 0.26 & \mathrm{NS}\end{array}$

$\mathrm{HDL}(\mathrm{mg} / \mathrm{dl}) \quad 30.80 \pm 7.55 \quad 35.29 \pm 8.30 \quad-2.190 .031 \mathrm{Sig}$

$\begin{array}{llllll}\mathrm{TC}: \mathrm{HDL} & 6.3 \pm 1.64 & 6 \pm 2 & .61 & 0.54 & \mathrm{NS}\end{array}$

LDL:HDL $\quad 4.05 \pm 1.56 \quad 3.8 \pm 1.59 \quad 55 \quad 0.59 \quad$ NS

**P value is obtained by independant sample $\mathrm{t}$ test.
The table shows that there was significant inverse association of hyperhomocysteinemia with HDL. Other parameters of lipid profile and lipid ratios did not show any significant association.

\section{Table-IV}

Sex distribution of the hyperhomocysteinemic subjects according to lipid profile

Hyperhomocysteinemia

\begin{tabular}{lcc} 
Parameters & Male $(\mathrm{n}=13)$ & Female $(\mathrm{n}=7)$ \\
\hline TC $(\mathrm{mg} / \mathrm{dl})$ & $189.15 \pm 37.48$ & $181.29 \pm 22.23$ \\
TG $(\mathrm{mg} / \mathrm{dl})$ & $190.46 \pm 65.69$ & $162.14 \pm 90.65$ \\
LDL $(\mathrm{mg} / \mathrm{dl})$ & $120.23 \pm 33.34$ & $116.43 \pm 29.8$ \\
HDL $(\mathrm{mg} / \mathrm{dl})$ & $30.15 \pm 6.63$ & $32 \pm 9.49$ \\
TC:HDL & $6.39 \pm 1.23: 1$ & $6.14 \pm 2.33: 1$ \\
LDL:HDL & $4.03 \pm 1.05: 1$ & $4.07 \pm 2.34: 1$ \\
\hline
\end{tabular}

The table shows that among the hyperhomocysteinemic subjects male had higher TC, TG, LDL and TC:HDL ratio than the female. Female had higher HDL and LDL:HDL ratio than the male.

Table-V

Sex distribution of the normohomocysteinemic subjects according to lipid profile

Normohomocysteinemia $(\mathrm{n}=75)$

\begin{tabular}{lcc} 
Parameters & Male $(\mathrm{n}=31)$ & Female $(\mathrm{n}=44)$ \\
\hline TC $(\mathrm{mg} / \mathrm{dl})$ & $193.03 \pm 39.14$ & $207.5 \pm 41.51$ \\
$\mathrm{TG}(\mathrm{mg} / \mathrm{dl})$ & $188.93 \pm 129.39$ & $214.3 \pm 123.24$ \\
$\mathrm{LDL}(\mathrm{mg} / \mathrm{dl})$ & $125.07 \pm 31.69$ & $131.9 \pm 39.54$ \\
$\mathrm{HDL}(\mathrm{mg} / \mathrm{dl})$ & $34.1 \pm 9.1$ & $36.14 \pm 7.69$ \\
$\mathrm{TC}: \mathrm{HDL}$ & $5.89 \pm 1.75$ & $6.08 \pm 2.18$ \\
LDL $:$ HDL & $3.8 \pm 1.5$ & $3.85 \pm 1.68$ \\
\hline
\end{tabular}

Table $\mathrm{V}$ shows that among the study subjects having no hyperhomocysteinemia, female had higher TC, TG, LDL, HDL, TC: HDL and LDL: HDL.

\section{Table-VI}

Correlation of serum total homocysteine with lipid profile Biochemical parameters tHcy

\begin{tabular}{lccc} 
& $\mathrm{r}$ & $\mathrm{p}$ & significance \\
\hline TC $(\mathrm{mg} / \mathrm{dl})$ & -0.136 & 0.188 & $\mathrm{NS}$ \\
TG $(\mathrm{mg} / \mathrm{dl})$ & -0.078 & 0.451 & $\mathrm{NS}$ \\
LDL $(\mathrm{mg} / \mathrm{dl})$ & -0.104 & 0.330 & $\mathrm{NS}$ \\
HDL $(\mathrm{mg} / \mathrm{dl})$ & -0.247 & 0.016 & $\mathrm{Sig}$ \\
TC $:$ HDL & 0.103 & 0.32 & $\mathrm{NS}$ \\
LDL $:$ HDL & 0.083 & 0.44 & $\mathrm{NS}$ \\
\hline
\end{tabular}

' $r$ ' value is obtained by pearsons correlation 
Table 6 shows that HDL had significant inverse correlation with serum total homocysteine. Other parameters of lipid profile and lipid ratios did not have any significant association with serum total homocysteine.

\section{Discussion:}

Hyperhomocysteinemia was found in $21.05 \%$ of our study population,. Among them $65 \%$ were male and $35 \%$ were female. A study in Belgium showed higher (31\%) prevalence of hyperhomocysteinemia and the population had higher prevalence of coronary artery disease, macroangiopathy and impaired renal function. ${ }^{14}$ In Pakistan higher frequency (82.8\%) was found in type 2 diabetic patients. They also found that for the most part, homocysteine elevation in patients with diabetes mellitus only occurs when renal function deteriorates. ${ }^{15}$ A review article also supported the statement. ${ }^{16}$

Mean serum tHcy concentration among the study population was $11.81 \pm 4.09 \mu \mathrm{mol} / \mathrm{L}$ in our study. Male had significantly higher mean than female. $(13.14 \pm 3.7$ vs $10.66 \pm 4.12 \mu \mathrm{mol} / \mathrm{L}$ ).

In Italy Mazza and his co-workers found lower serum homocysteine in type 2 diabetic patients. (7.7 $\pm 2.2 \mu \mathrm{mol} /$ L). They also found that men had significantly higher level than women. (13.0 $\pm 5.3 \mathrm{vs} 10.4 \pm 2.62 \mu \mathrm{mol} / \mathrm{L}, \mathrm{p}<0.0001) .{ }^{17}$ Another study in Italy also showed that fasting tHcy concentration was significantly higher in men than in women $(\mathrm{P}<0.001) .{ }^{18}$

In Turkey type 2 diabetic patients without cardiac disease showed that fasting serum total homocysteine was $9.66 \pm 3.23 \mu \mathrm{mol} / \mathrm{L}^{19}$

Another study in Turkey showed that mean plasma homocysteine concentrations was $10.64 \pm 0.53 \mu \mathrm{mol} / \mathrm{L}$ and $13.29 \pm 0.78 \mu \mathrm{mol} / \mathrm{L}$ in normo- and microalbuminuric diabetic patients. ${ }^{20}$

In a population based survey conducted in Japan, Adachi and his co-workers also showed that men had higher mean than female (12.6 \pm 5.5 vs 9.8 2.7$).{ }^{21}$ In Africa tHcy $(\mathrm{p}<0.01)$ was also significantly higher in the males when compared with the corresponding female value. ${ }^{22}$

In Hoorn study higher prevalence was found in male than female (27.5\% vs $13.3 \%) .{ }^{23}$ A study conducted in Pakistan also showed similar result. They found that among the hyperhomocysteinic diabetic patients $75.9 \%$ were male and $24.1 \%$ were female. ${ }^{15}$ These sex differences may be caused by the influence of female sex hormones.

Elevated levels of serum homocysteine may result from geographical variations, racial and ethnic differences, genetic causes, different lifestyle, inadequate intake of B vitamins and folate in the diet, inaccurate cooking of vegetables and not implementing fortification of grain products with folic acid.$^{24}$

Our study showed high TG $(198.96 \pm 116.71 \mathrm{mg} / \mathrm{dl})$ and low $\operatorname{HDL}(34.23 \pm 8.26 \mathrm{mg} / \mathrm{dl})$ in the study population. HDL had significant inverse correlation with serum tHcy. TC, TG and LDL all were found decreased in group having hyperhomocysteinemia. But there was no significant association. Lipid ratios did not show any significant association between two groups.

This is consistent with a study conducted in Belgium. They found that all the components of lipid profile were decreased in the group having hyperhomocysteinemia, though there was no significant relationship. ${ }^{14}$

In Turkey also researchers found no association between plasma homocysteine levels and total cholesterol, triglyceride, HDL-cholesterol and LDL-cholesterol . ${ }^{19}$

Our study differs with the study conducted by Faulkner. He found significant association among tHcy and lipoproteins in subjects with type $2 \mathrm{DM}$ : TC $(r=0.65, P=$ $0.01)$ and triglycerides $(r=0.68, P=0.008) .{ }^{25}$

In Japan serum triglyceride levels were strongly found to be associated with tHcy in diabetic men only. ${ }^{26}$ In another study in Japan, significant inverse correlation with serum tHcy was observed. ${ }^{21}$

Serum TG was found to be positively associated with serum tHcy in type 2 diabetes in India also. ${ }^{27}$

\section{Conclusion:}

From this study it may be concluded that more than one fifth of the type 2 diabetic patients had hyperhomocysteinemia among which male were predominant over female. Mean serum tHcy level of the population was $11.81 \pm 4.09 \mu \mathrm{mol} / \mathrm{L}$ and male had higher mean than female. The group with hyperhomocysteinemia had significantly lower HDL than the other group.

\section{Recommendations:}

As the study results showed patient with hyperhomocysteinemia had significantly lower HDL and higher TAG,TC \& LDL which are associated with increased adverse cardiovascular events, the study can be conducted on a large sample to confirm the findings.

\section{References}

1. International Diabetes Federation: Diabetes prevalence [article online]. Accessed 1 July 2012 < www.idf.org/home/ index.cfm? node $=264$. $>$

2. Akhter A, Fatema K, Afroz A, Bhowmik B, Ali L and Hussain A. Prevalence of Diabetes Mellitus and its Associated Risk Indicators in a Rural Bangladeshi Population. The Open Diabetes Journal 2011; 4: 6-13.

3. Sayeed MA, Mahtab H., Khanam PA, Latif ZA, Banu A and Khan AK. Prevalence of diabetes and impaired fasting glucose 
in urban population of Bangladesh, Bangladesh Med Res Counc Bull 2007; 33(1):1-12.

4. Boucher JL and Hurrell DG. Cardiovascular Disease and Diabetes. Diabetes Spectrum 2008; 21(3):154-155

5. Grundy SM, Benjamin IJ, Burke GL, Chait A, Eckel RH, Howard BV,et al. Diabetes and Cardiovascular disease -A statememt for the Health care Professional From American Heart Association. Circulation 1999; 100: 1134-1146

6. Hopkins PN, Hunt SC, Wu LL, Williams GH and Williams RR. Hypertension, dyslipidemia, and insulin resistance: links in a chain or spokes on a wheel. Curr Opin Lipidol 1996; 7: 241-253.

7. Audelin MC and Genest Jr J. Homocysteine and Cardiovascular disease in Diabetes Mellitus, Atherosclerosis 2001; 159(2): 497-511.

8. Maron DJ, Rider PM, Grundy SM, Prevention Strategies for Coronary Heart Disease, In : Fuster V, Walsh RA, O'rourke RA, Wilson PP, editors, Hurst's, the heart, $12^{\text {th }}$ edition, Mc Graw Hill, New York, USA,2008:1235

9. Brustolin S, Giugliani R and Félix TM. Genetics of homocysteine metabolism and associated disorders. Braz J Med Biol Res 2010; 43(1):1-7.

10. Fonseca V, Guba SC and Fink LM. Hyperhomocysteinemia and the endocrine system: implications for atherosclerosis and thrombosis. Endocr Rev 1999; 20:738-759.

11. Fonesca V, Desouza C, Asnani S and Jialal I. Nontraditional Risk Factors for Cardiovascular Disease in Diabetes, Endocrine Reviews 2004; 25(1):153-175.

12. Mooradian A D. Dyslipidemia in type 2 diabetes mellitus. Nature Clinical Practice, Endocrinology \& Metabolism 2009; $5(3)$.

13. Chait A, Malinow MR, Nevin DN, Morris CD, Eastgard RL et a1. Increased dietary micronutrients decrease serum homocysteine concentrations in patients at high risk of cardiovascular disease. Am J clin Nutr. 1990; 70:881-7.

14. Buysschaert M, Allemacq PE, Dramais AS and Hermans MP. Hyperhomocysteinemia in Type 2 Diabetes, Relation to macroangiopathy, nephropathy and insulin resistance. Diabetes Care 2000; 23(12):1816-1822.

15. Shaikh MK, Devrajani BR, Shaikh A, Ali Shah SZ, Shaikh S.and Singh D. Plasma Homocysteine Level in Patients with Diabetes mellitus. World Applied Sciences Journal. 2012; 16(9):1269-1273.

16. Elias AN and Eng S. Homocysteine concentrations in patients with diabetes mellitus - relationship to microvascular and macrovascular disease. Diabetes, Obesity and Metabolism. $2005 ; 7: 117-121$
17. Mazza A, Bossone E, Mazza F. and Distante A. Reduced serum homocysteine levels in type 2 diabetes. Nutr Metab Cardiovasc Dis. 2005;1(2):118-24.

18. Russo GT, Di Benedetto A, Giorda C, Alessi E, Crisafulli G, Ientile R, et al. Correlates of total homocysteine plasma concentration in type 2 diabetes. Eur J Clin Invest. 2004; 34(3):197-204.

19. Tarkun I, Arslan BC, Cantürk Z, Tarkun P, Kozdað G. and Topsever P. Homocysteine Concentrations in Type 2 Diabetes Mellitus Patients Without Cardiovascular Disease: Relationship to Metabolic Parameters and Diabetic Complications, Turkish Journal of Endocrinology and Metabolism. 2003;1: 11-17

20. Ozmen B, Ozmen D, Turgan N, Habif S, Mutaf I and Bayindir O. Association Between Homocysteinemia and Renal Function in Patients with Type 2 Diabetes Mellitus.Annals of Clinical \& Laboratory Science. 2002; 32(3): 279-287

21. Adachi H, Hirai Y, Fujiura Y, Matsuoka H., Satoh A. and Imaizumi T. Plasma Homocysteine Levels and Atherosclerosis in Japan: Epidemiological Study by Use of Carotid Ultrasonography, Stroke. 2002; 33: 2177-2181.

22. Ebesunun MO and Obajobi EO.Elevated plasma homocysteine in type 2 diabetes mellitus:a risk factor for cardiovascular diseases. The Pan African Medical Journal. 2012; 12(48):18.viewed 18 Aug 2012. <www.panafricanmed journal.com/content/article/12/48/full/>

23. Hoogeveen EK, Kostense P k, Jakobs C, Dekker JM, Nijpels G, Heine RJ, et al. Hyperhomocysteinemia increase risk of death, especially in type 2 diabetes : A 5 year follow up of Hoorn Study, Circulation. 2000;101: 1501-1506

24. Alam N, Khan HILR, Chowdhury AW, Haque MS, Ali MS, Sabah KMN, et al. Elevated serum homocysteine level has a positive correlation with serum cardiac troponin I in patients with acute myocardial infarction, Bangladesh Med Res Coun Bull. 2012;38: 9-13.

25. Faulkner MS, Chao WH, Kamath SK, Quinn L, Fritschi C, Maggiore JA et al. Total Homocysteine, Diet, and Lipid Profiles in Type 1 and Type 2 Diabetic and Nondiabetic Adolescents .Cardiovasc Nurs 2006; 21(1): 47-55

26. Masuda Y, Kubo A, katsuki Kokaze A, Yoshida M, Fukuhara N.and Takashima Y. Factors associated with serum total homocysteine level in type 2 diabetes, Environ Health Prev Med 2008;13:148-155.

27. Ramachandran L, Negi NS, Gupta B. Prevalence of hyperhomocysteinaemia in type-2 diabetes mellitus and its correlation with its complications. Journal, Indian Academy of Clinical Medicine 2012; 13(4 1): 277-81. 